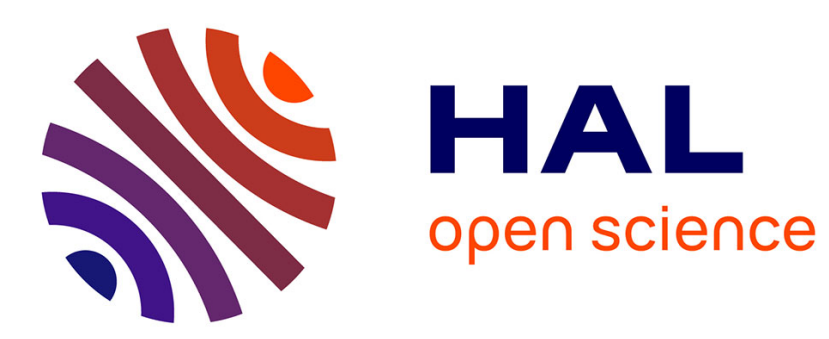

\title{
Euclid's Common Notions and the Theory of Equivalence
}

Vincenzo de Risi

\section{To cite this version:}

Vincenzo de Risi. Euclid's Common Notions and the Theory of Equivalence. Foundations of Science, 2020, 10.1007/s10699-020-09694-w . hal-03058635

\section{HAL Id: hal-03058635 \\ https://hal.science/hal-03058635}

Submitted on 11 Dec 2020

HAL is a multi-disciplinary open access archive for the deposit and dissemination of scientific research documents, whether they are published or not. The documents may come from teaching and research institutions in France or abroad, or from public or private research centers.
L'archive ouverte pluridisciplinaire HAL, est destinée au dépôt et à la diffusion de documents scientifiques de niveau recherche, publiés ou non, émanant des établissements d'enseignement et de recherche français ou étrangers, des laboratoires publics ou privés. 


\section{Euclid's Common Notions and the Theory of Equivalence}

Vincenzo De Risi

The "common notions" prefacing the Elements of Euclid are a very peculiar set of axioms, and their authenticity, as well as their actual role in the demonstrations, have been object of debate. In the first part of this essay, I offer a survey of the evidence for the authenticity of the common notions, and conclude that only three of them are likely to have been in place at the times of Euclid, whereas others were added in Late Antiquity. In the second part of the essay, I consider the meaning and uses of the common notions in Greek mathematics, and argue that they were originally conceived in order to axiomatize a theory of equivalence in geometry. I also claim that two interpolated common notions responded to different epistemic needs and regulated diagrammatic inferences.

\section{\$1. Introduction}

The Elements of Euclid are introduced by three sets of principles: definitions, postulates and

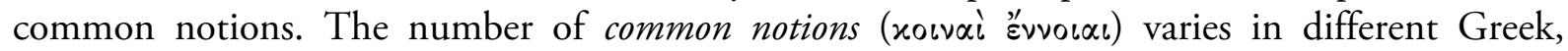
Arabic and Latin manuscripts. Most of these manuscripts comprise either nine or ten of them. Ancient commentators inform us that still further principles had been suggested in late antiquity but never found their way into the text of the Elements. ${ }^{1}$ Following the textual indications of these commentaries and other philological considerations, Johan Ludvig Heiberg produced a critical edition of the Elements containing five of these common notions:

CN1: Things which are equal to the same thing are also equal to one another.

CN2: If equals be added to equals, the wholes are equal.

$\mathrm{CN} 3$ : If equals be subtracted from equals, the remainders are equal.

CN4: Things which coincide with one another are equal to one another.

CN5: The whole is greater than the part.

This list is accepted nowadays by most historians of mathematics, all of whom agree with Heiberg's excision of many other principles from the text. Nonetheless, a few authoritative

Aknowlwdgments. I thank Gregg de Young, Eduardo Giovannini, Marco Panza, and an anonymous referee, for their insightful remarks. I am especially grateful to Mattia Mantovani, whose many suggestions and relentless requests of better evidence substantially improved the final version of this essay.

${ }^{1}$ For a first appraisal of the number of common notions in various manuscripts and Euclidean editions, see my $\mathrm{V}$. DE RISI, The Development of Euclidean Axiomatics. The systems of principles and the foundations of mathematics in editions of the Elements from Antiquity to the Eighteenth Century, "Archive for History of Exact Sciences", 70 (2016), pp. 591-676. 
scholars, such as Thomas Heath or Ian Mueller, have doubted the authenticity of the last two

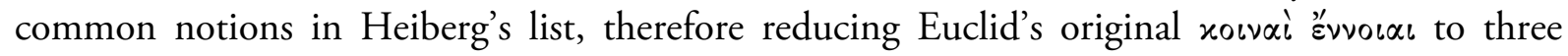
statements only. ${ }^{2}$

Since there is no consensus on the matter, I offer here a survey of the current evidence for the authenticity of Heiberg's five common notions and some new grounds for debate. In particular, in $\$ 2$ I offer textual arguments based on the reference to common notions in the propositions of the Elements as well as in indirect ancient sources. I show that, while CN1-CN3 are solidly embedded in the Euclidean text and often mentioned in the earlier Greek tradition, CN4 and $\mathrm{CN} 5$ are only tenuously connected with the text of the Elements and do not appear in other ancient sources before the fifth century CE. I conclude that the last two common notions are most probably spurious and I advance the conjecture that they were interpolated by Theon of Alexandria.

In the second half of the essay, I consider the meaning and uses of the common notions in Greek mathematics. I argue ( $\$ 3$ ) that they were originally conceived in order to axiomatize a theory of equivalence in geometry and I offer an interpretation of their role in Euclid's Elements. I conclude, without making reference to the philological arguments of $\$ 2$, that while CN1-CN3 were clearly used by Euclid as principles of a theory of equiampliability, CN4 and CN5 were external to the theory developed in the Elements and responded to different epistemic needs. In particular, I claim $(\$ 4)$ that $\mathrm{CN} 4$ and $\mathrm{CN} 5$ are employed in diagrammatic reasoning and display a different underlying epistemology than the purely propositional principles CN1-CN3. The latter argument sheds some light on the Greek mathematical practices and reinforces the conclusion that $\mathrm{CN} 4$ and $\mathrm{CN} 5$ were later additions to the text of the Elements.

\section{\$2. Textual Evidence for the Common Notions}

Interpreters do generally agree that the first three common notions are authentic. An almost

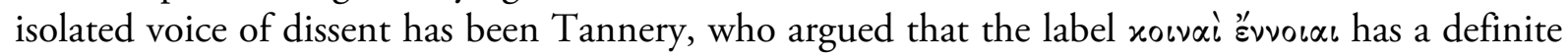
Stoic ring to it and that, therefore, the list of principles was probably interpolated during the Hellenistic Age. While it is hard not to agree with Tannery that the name of the principles might not be Euclid's, modern interpreters generally acknowledge that the principles themselves are. ${ }^{3}$

We posses several pieces of evidence that point in this direction. First of all, these common notions are very well represented in the text of the Elements themselves. Indeed, CN1, CN2 and $\mathrm{CN} 3$ are at work in a great number of theorems. Euclid rarely spells out the statements of the common notions in the course of the proofs but he adds clear textual indications that he is about to make an inference supported by some principle. He says, for instance, that " $D A$ is equal to $D B$, and therefore (' $\propto \rho \alpha)$ the remainder $A L$ is equal to $B G^{\prime \prime}$, with $\alpha^{\prime} \rho \alpha$ (or some similar particle) normally

\footnotetext{
${ }^{2}$ See T.L. HeAth (ed.), Euclid. The Thirteen Books of the Elements, Cambridge, CUP 1925², vol. 1, pp. 225 and 232; and I. Mueller, Philosophy of Mathematics and Deductive Structure in Euclid's Elements, New York, Dover 1981, p. 35. More recently, B. VITRAC (ed.), Euclide. Les Eléments, Paris, PUF 1990-2001, vol. 1, pp. 181-84, is inclined to consider CN4 spurious and CN5 authentic.

${ }^{3}$ See P. TANnery, Sur l'authenticité des axiomes d'Euclide, "Bulletin des sciences mathématiques et astronomiques", 8 (1884), pp. 162-175. Tannery's thesis has been effectively rebutted by HEATH, The Elements, vol. 1, pp. 221-22. For an appraisal, see R.B. TODD, The Stoic Common Notions: A Re-examination and Reinterpretation, "Symbola Osloenses”, 48 (1973), pp. 47-75.
} 
signaling a reference to a previous theorem (moreover, the word for "remainder" is the same as, or a minimal variation on, the one employed in CN3). ${ }^{4}$ In particular, CN1 is the only common notion explicitly spelled out verbatim in three proofs of the first book of the Elements. ${ }^{5}$ Both CN2 and CN3 are, however, also mentioned in Euclid's Data, and this is also a further strong argument for their authenticity. ${ }^{6}$

We also have additional evidence from indirect sources.

Principles akin to CN2 and CN3 are mentioned in passing in Plato's Theaetetus and Parmenides (even though their spelling does not match up with Euclid's). ${ }^{7}$ More importantly, we are informed by Aristotle that the mathematicians of his time had advanced some new principles, which they labeled common axioms ( $\left.\operatorname{cov}^{\prime} \dot{\alpha} \dot{\alpha}_{\iota} \iota \omega \mu \alpha \tau \alpha\right)$ in so far as they were common to all mathematical disciplines and, in particular, to both the theory of numbers (arithmetic) and the theory of magnitudes (geometry). Aristotle belabored the theory of common axioms quite a bit and integrated it into his more general philosophy of science by associating mathematical common axioms with other kinds of universal or formal principles such as the Principle of Contradiction. ${ }^{8}$ In the course of these discussions, Aristotle repeatedly mentioned CN3 in almost the exact same terms as those used by Euclid. ${ }^{9}$ It is, therefore, reasonable to surmise that $\mathrm{CN} 3$, and probably $\mathrm{CN} 2$ too, were in place as principles of mathematics already in the age of Aristotle.

The picture that we get from Aristotle's presentation and from Plato's scantier references is that such principles were probably first conceived in the fourth century and were employed for stating general theorems about different kinds of geometrical magnitudes and numbers. ${ }^{10}$ On this understanding of things, Plato's late dialogues would be testimony to a still-inchoative state of

\footnotetext{
${ }^{4}$ Elements I, 2. MuEller, Philosophy of Mathematics and Deductive Structure, has especially stressed the importance of this kind of deductive clause. For a full account, see F. ACERBI, La sintassi logica della matematica greca, 2011, online. ${ }^{5}$ Elements I, 1, 2 and 13.

${ }^{6}$ They are employed, for instance, in Data 3 and 4 respectively. It may be noted, however, that the spelling of CN3 is clearer than that of CN2 (and recurs again in Data 12): see belownote@60.

7 @59. Plato, Theaet. 155a: "And as we consider them, I shall say, I think, first, that nothing can ever become more or less in size or number, so long as it remains equal to itself. Is it not so? ... and secondly, that anything to which nothing is added and from which nothing is subtracted, is neither increased nor diminished, but is always equal" (transl. Fowler). The correspondence with Euclid's common notions is admittedly quite vague, and the Platonic principles have a much more metaphysical aspect. It is remarkable, however, that they appear in a dialogue on scientific knowledge conducted by a young mathematician. If we suppose that Euclid's common notions were developed in the generation of Theaetetus and Eudoxus, it may perhaps be considered a stroke of Platonic irony to imagine that they were notions advanced by an aged Socrates while a receptive stripling well versed in mathematics nodded in approval. See also PLATO, Parm. 154b: "For adding equals to unequals, in time or anything else whatever, always makes the difference equal in the amount by which the unequals originally differed" (transl. Allen). We are informed by Proclus (In Euclidis 197) that Pappus had proposed to add a similar common notion to the principles of Euclid, but we have no trace of it in any Greek manuscript of the Elements. It first appears as an interpolation in Gerardo da Cremona's Latin translation (from the twelfth century) and passed from there over into several early modern editions of the Elements, such as Clavius' (1574).

${ }^{8}$ The most important passages are in An. Post. A 2, 72a14-24; An. Post. A 10, 76a41-42; Metaph. Г 3, 1005b12-20. ${ }^{9} @ 61$. See An. Pr. A 24, 41b22-23; An. Post. A 10, 76a41-42; A 10, 76b21; A 11, 77a26-31; Metaph. K 4, 1061 b20. On Aristotle's theory of axioms see my V. DE RISI, Aristotle on Common Axioms, in F. Ademollo, F. Amerini, V. De Risi (eds.), Thinking and Calculating. Essays on Logic, its History and its Applications, New York, Springer (forthcoming).

${ }^{10}$ For a few Aristotelian passages on a universal mathematical science, see An. Post. A 5, 74a17-25; A 24, 85a37-85b1; Metaph. Г 2, 1004a2-9; E 1, 1026a25-27; K 7, 1064b7-9. For a discussion of the topic, see D. RABOUIN, Mathesis Universalis. L'idée de “mathématique universelle” d'Aristote à Descartes, Paris, PUF 2009.
} 
discussion, while Aristotle's Posterior Analytics, written later, would suggest that a fuller theory had already been developed. We also know that the text of the Elements draws heavily on earlier mathematical sources and in particular on the works of Eudoxus and Theaetetus (who lived in the generation between Plato and Aristotle). It is therefore quite natural to think that Euclid drew

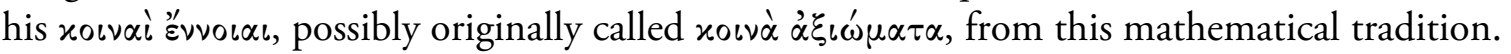

The indirect evidence for the first common notion $\mathrm{CN} 1$ is less compelling but nonetheless quite strong. It is quoted in some later commentaries on Aristotle's works (such as Alexander's) but Proclus also tells us that Apollonius had attempted to prove it, thereby showing that $\mathrm{CN} 1$ was considered to be authentically Euclidean already a few generations after Euclid. Galen adds that Carneades (second century BCE) had challenged it using skeptical arguments. ${ }^{11}$ Given the sources at our disposal, it might be conjectured that $\mathrm{CN} 1$ was devised by Euclid himself, whereas $\mathrm{CN} 2$ and $\mathrm{CN} 3$ had been already formulated in the generation of Eudoxus. This would dovetail with the more abstract character of $\mathrm{CN} 1$ with respect to $\mathrm{CN} 2$ and $\mathrm{CN} 3$; with the fact that Aristotle made no mention of it; and with the explicit quotations of CN1 to be found in the first book of the Elements (and in this first book alone), this being probably the book most extensively reworked and rewritten by Euclid himself. ${ }^{12}$

By contrast, the textual evidence concerning $\mathrm{CN} 4$ and $\mathrm{CN} 5$ is strikingly poor.

The common notion on coincidence (CN4) appears to be employed only three times in the Elements, namely, on the occasions on which Euclid resorts to the procedure of superposition: Elements I, 4 and 8, and Elements III, 24. In these propositions Euclid makes no explicit reference to CN4 in the form in which we know it but rather employs different expressions to convey the idea that coincident figures are equal. In Elements I, 4, Euclid simply claims, in passing, that "the base $B C$ will coincide with the base $E F$ and will be equal to it", and this sentence does not look like an inference from a general principle about congruence and equality. In the same proposition Euclid also tacitly assumes, in the same way, the converse propositions that, if two angles or two segments are equal, they will coincide when superposed: "the point $B$ will also coincide with $E$, because $A B$ is equal to $D E$ "; and "the straight line $A C$ will also coincide with $D F$, because the angle $B A C$ is equal to the angle $E D F$ ' ${ }^{13}$ These two principles are, however, not stated as common notions in the Elements and the uniformity of the language in the three instances strongly suggests a uniform epistemological interpretation: Euclid was not employing here any inference from axioms and rather endorsed a non-axiomatic approach to the relation between congruence and equality, freely moving between the two notions.

The connection of CN5 ("the whole is greater than the part") with the text of the Elements is equally tenuous: in this case too, Euclid never explicitly mentions this principle in the

\footnotetext{
${ }^{11} @ 46$. Alexander's reference to CN1 is in In metaph. 265. Proclus' testimony regarding Apollonius is to be found in In Euclidis 194-95. Galen's reference to Carneades is to be found in De optima doctrina, $₫ 2$ (ed. Kuhn, vol. 1, p. 45). $12 @ 64$. The lack of any reference to CN1 in Aristotle seems to be an especially telling detail, since the latter's logical works surely offered many opportunities for such a principle to be spelled out, for example in the context of the exposition of syllogistic. A similar case seems to obtain with regard to Elements V, 11, which proves that, if two ratios are equal to a third, they are also equal to one another, and does so without recurring to $\mathrm{CN} 1$. It is possible that $\mathrm{CN} 1$ had not yet been formulated at the time at which Eudoxus composed the theory of this book; it is also possible, however, that the status of ratios in ancient mathematics did not allow them to be treated as "things" in the sense of other mathematical entities referred to by the Euclidean common notions.

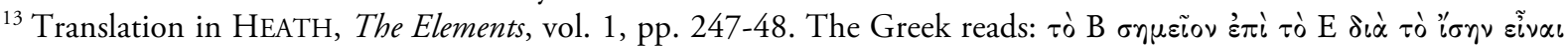

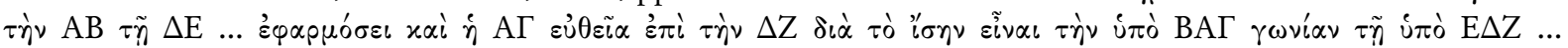

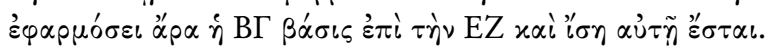


demonstrations. All we have are several occurrences of the sentence "but then the less would be equal to the greater, which is impossible" (or similar formulations) in the course of reductio arguments in which Euclid compares two figures. ${ }^{14}$ Several ancient and modern authors have seen in these passages a reference to $\mathrm{CN} 5 .{ }^{15}$ The standard formulation regarding the greater and the less, however, does not correspond very closely to CN5 and fails to refer to the whole and the part. The same formula, moreover, is to be found in the course of the demonstrations developed by certain pre-Euclidean authors such as Autolycus - who did not have any axiom regarding part and whole. ${ }^{16}$ The occurrence of such an expression in the Elements seems, then, to have to be understood as something derived from earlier sources, rather than as an appeal to an explicit principle (and certainly not to CN5, which has a different phrasing). It simply never happens that Euclid, anywhere in the course of the Elements, claims that the whole is greater than the part. ${ }^{17}$

The secondary sources also speak against the authenticity of these common notions.

Aristotle never mentions CN4 or CN5 despite dealing several times with common axioms and their epistemology. Had they been in place as axioms of mathematics during his lifetime (having been formulated, say, by Eudoxus), it would be strange that Aristotle never referred to them-be it either as confirmations of, or as foils to, his own views. The specificity of these notions (as compared to the axioms on equality CN1-CN3) should, had they been known to Aristotle, have been worthy of some consideration and the fact that they are never referred to by him seems to me to be fairly strong evidence of their not yet having been formulated at the time of Aristotle's writing.

Aristotle's theory of common axioms has often been considered to be a strong argument against the authenticity of CN4 in particular, since the technique of superposition does not seem to apply to numbers or to magnitudes in general. Being properly geometrical, so it is claimed, CN4 fails to comply with the epistemology underlying Euclid's common notions. ${ }^{18}$ This standard argument has some strength but it should not be overestimated. We do not really know whether Euclid endorsed Aristotle's views on the epistemology of common axioms, and a case could be made that numbers may "coincide" with one another after all. ${ }^{19}$ The matter is even more complicated from a textual point of view. Notwithstanding Aristotle's theory about the

\footnotetext{
${ }^{14}$ Mentions of similar sentences are to be found in a great number of propositions, and while Tannery, Heath or Mueller only quote Elements I, 6, they can easily be read also in Elements I, 39, in Elements III, 2, 4, 5, 6, 11, and many other propositions. Cf. also VITRAC, Les Eléments, vol. 1, pp. 182-84.

${ }^{15}$ At least starting from PROCLUS, In Euclidis 264. Modern editions of the Elements generally refer back to CN5 every time Euclid employs the sentence on the greater and the less.

${ }^{16}$ AutolyCus, De sphaera, prop. 3 (p. 12 Hultsch). Cf. ViTraC, Les Éléments, vol. 1, p. 182, n. 18.

${ }^{17}$ It happened, sometimes, that explications were interpolated into the text making reference to something like CN5. But not even in these cases does the exact formulation of CN5 ever appear. See, for instance, a textual interpolation into Elements XII, 12 quoted by Heiberg (ad loc.): here Euclid says that a cone is bigger than a pyramid, and an interpolated passage adds "since the former contains the latter". No mention is made, however, of the notions of "whole" or "part".

${ }^{18}$ See for instance TANNERY, Sur l'authenticité des axiomes d'Euclide, but the claim is endorsed by Heath, von Fritz, and very many other scholars.

${ }^{19}$ In Greek mathematics, numbers are collections of objects and these may possibly "coincide" with one another. Notice, in any case, that the formulation of CN4 is such as to only mention "things" in general (the Greek uses the neuter pronoun), just as occurs with $\mathrm{CN} 1-\mathrm{CN} 3$. If CN4 was to apply only to figures, or geometrical magnitudes, whoever stated it could have just said so. For a similar opinion, see B. EINARSON, On Certain Mathematical Terms in Aristotle's Logic, "The American Journal of Philology", 57 (1936), pp. 33-54, and 151-72; p. 43 n. 52 and p. 47 n. 67.
} 
applicability of $x \circ \iota \nu \dot{\alpha} \dot{\alpha} \xi \iota \omega \mu \alpha \tau \alpha$ to both arithmetic and geometry, the arithmetical books of the Elements display almost no sign of any common notions. Common notions CN4 and CN5 do not make any appearance in number theory, but $\mathrm{CN} 1-\mathrm{CN} 3$ too only feature in three demonstrations of Book VII (Elements VII, 5, 7, and 8), and even these do not mention them in a very explicit way. ${ }^{20}$ No common notions are employed in the following arithmetical Books VIII and IX. As a matter of fact, Euclid's reliance on previous material in composing the Elements may even suggest that the arithmetical books were written (possibly in the Pythagorean school) before the introduction of the common axioms as principles of demonstration or, in any case, outside of the axiomatic tradition of Eudoxus and Theaetetus. ${ }^{21}$ It is very likely, then, that a further systematization of arithmetic (either due to Euclid himself or to someone belonging to the previous generation) introduced references to these principles into the first propositions in which they were needed. In conclusion, even if we want to insist on the geometrical character of CN4 and use this argument as a criterion for excision, it should be taken into account that all the common notions are employed practically exclusively in the geometrical books alone. In conclusion, then, I would consider Aristotle's theory to constitute a good negative argument for the rejection of CN4 (he did indeed make no mention of it), but not such a good positive one.

The extant mathematical works by Archimedes, Geminus, Zenodorus, and, later on, Pappus mention neither CN4 nor CN5.22

Apollonius (third century BCE) also seems to have been unaware of these latter notions. He had attempted to prove common notions about equality, and CN1 in particular, by arguing that

\footnotetext{
${ }^{20} @ 60$. I will not belabor the point here, but it is remarkable that the only principle that seems to be spelled out more clearly in the arithmetical books is, precisely, CN3. It is quoted in some recognizable way, even if not literally, in both Elements VII, 7 and 8. It must be borne in mind that this is the only principle quoted by Aristotle as common to arithmetic and geometry. He may have had in mind some specific theorems to this effect and possibly a pre-Euclidean version of one of these two propositions.

${ }^{21}$ B.L. VAN DeR WAERden, Zur Geschichte der Grieschichen Mathematik, Darmstadt, WB 1965, has especially insisted that the content of Books VII-IX must be understood to precede the mathematical work of Theaetetus and we have seen that the latter may be considered a terminus post quem for the formulation of the common notions (see note@59). There is no doubt, in any case, that the material of the arithmetical books was reworked in later times. For a recent appraisal of the matter, see K. SAITO, Re-examination of the different origins of the arithmetical books of Euclid's Elements, "Historia Mathematica", 47 (2019), pp. 39-53.

$22 @ 70$. Archimedes' only use of something like CN4 is in Conoids and Spheroids 18, where he shows that the two halves of a spheroid cut by a plane passing through its center are "equal", by showing that they are congruent. No consideration of measure, however, is involved here, and even though in the last sentence of the demonstration

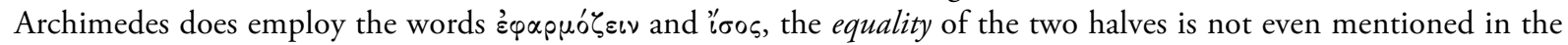
statement of the proposition. Archimedes is rather interested, throughout, only in congruence, and equality of size is

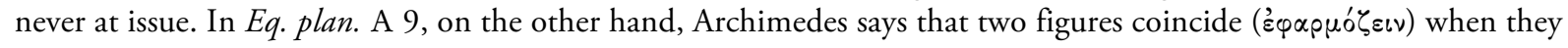

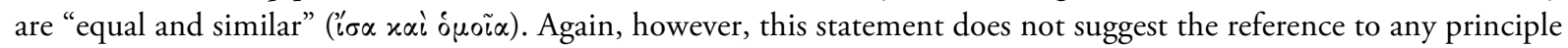
entailing equality from congruence. Neither CN4 and CN5 are mentioned by Proclus in relation to Geminus' many considerations on axiomatics. Zenodorus' theorems on isoperimetric figures (second century BCE) would have easily allowed inferences through $\mathrm{CN} 4$ and $\mathrm{CN} 5$, but they are nowhere mentioned. These theorems are to be found in Theon's commentary on Ptolemy's Almagest and again in Pappus' Collectiones E 1-19 (see also F. HulTSCH (ed.), Pappi Alexandrini collectionis quae supersunt, Berlin, Weidmann 1875-1878, vol. 3, pp. 1190-1211). Pappus himself makes an inference from congruence to equality in Collectiones $\Delta 39$ but I am not aware of any further passage in the corpus and the latter seems to be too isolated to make a case for the existence of an explicit axiom to this effect. The passage reports a demonstration by Nicomedes, and we cannot say whether the reference to superposition was already in Pappus' source.
} 
all equal things may occupy the same place. ${ }^{23}$ In this connection we might expect a reference to CN4 on superposition, either to prove CN4 (as well as CN1) through the notion of sameness of place or perhaps to ground sameness of place on superposition (details are too scanty to figure out what Apollonius was attempting to do with his proofs). ${ }^{24}$ Proclus, however, in reporting Apollonius' views, does not mention CN4 at all. We know that Apollonius had worked on homeomeric lines, i.e. on lines whose parts may be superposed. In Book VI of the Conics, Apollonius explicitly employs the notion of superposition at a foundational level, by defining equal conic sections as curves that can be superposed. The definition is then systematically exploited in the course of the book, which in turn never makes any, even implicit, use of CN4Apollonius nowhere infers equality from congruence, except for conic sections, and according to their definition. Of course, no firm conclusions may be drawn from a silence. Nonetheless, it is hard to believe that, in the course of the Conics, or in what we know about his work on homeomeric lines, Apollonius never referred to the one common notion of the Elements expressly dealing with superposition; unless, of course, CN4 was simply not there at the time. ${ }^{25}$

In any case, the formulation of a relation between equality and superposition by way of a definition, although surely adequate to Apollonius' aims in the Conics, seems to predate the formulation of a general axiom connecting these two notions: this axiom would indeed make Apollonius' definitions redundant.

Among other later - and more dubious - Latin sources, ps.-Censorinus (possibly third century CE) and Martianus Capella (fourth century) only mention CN1-CN3; Boethius (sixth century) also refers to $\mathrm{CN} 4$ but not to $\mathrm{CN} 5 .{ }^{26}$ The Aristotelian commentators of the third and fourth centuries (Alexander and Themistius) did not mention these principles in their studies on axiomatics. Commentators of the sixth century, however, such as Philoponus and Simplicius, did do so. $^{27}$

The two common notions are also mentioned by Proclus (fifth century), who provides one further important piece of information. He states that Heron (first century CE), in his lost commentary on the Elements, only accepted the first three common notions, therefore "reducing

\footnotetext{
${ }^{23}$ I may note that Apollonius' proof of $\mathrm{CN} 1$, based on sameness of place, seems to take this common notion as a geometrical axiom. This may fit with a general interpretation of them as principles for a theory of equivalence (see below, \$3).

${ }^{24}$ For Apollonius' proof, see above, note @46. Ibn al-Haytham offered a proof of $\mathrm{CN} 1$ grounded on superposition and CN4: see A. IGHBARIAH, R. WAGNER, Ibn al-Haytham's Revision of the Euclidean Foundations of Mathematics, "HOPOS: The Journal of the International Society for the History of Philosophy of Science", 8 (2018); and R. RASHED, Ibn al-Haytham, Ibn Sinnā, al-Ṭüsĩ : égalité ou congruence, "Arabic Science and Philosophy", 29 (2019), pp. 157-70. It is not clear whether Al-Haytham may have been aware of Apollonius' attempt (he seems not to have known Proclus' commentary on Euclid), but his proof of CN1, so similar to Apollonius', clearly points to the possibility of envisaging a foundation of $\mathrm{CN} 1$ by $\mathrm{CN} 4$.

${ }^{25}$ Apollonius made use of superposition only in Book VI of the Conics. He sometimes employed the converse of CN4 by assuming that equal segments may be superposed (e.g. in Conica VI, 4); and in Conica VI, 5 (only) he may have used an implicit inference of the form of CN4 but in such vague terms that he did not seem to have in mind any axiom to this effect. On homeomeric lines in Apollonius, see F. ACERBI, Homeomeric lines in Greek mathematics, "Science in Context", 23 (2010), pp. 1-37.

${ }^{26}$ CEnSORInus, De die natali liber, ed. F. Hultsch, Leipzig, Teubner 1867, pp. $62-63$ (it is a spurious fragment accompanying Censorinus' main work). MaRTIANUS CAPELlA, De nuptiis Philologiae et Mercurii, ed. A. Dick and J. Préaux, Stuttgart, Teubner 1969, Book VI, $\$ \$ 722-23$. M. FOLKERTS, "Boethius" Geometrie II, Stuttgart, Steiner 1970, pp. 117-18 and 184-85.

${ }^{27}$ PHILOP. In an. post. 10-11, and 123 (Wallies). See below for Simplicius.
} 
the principles to the lowest possible number" ${ }^{28}$ From Proclus' quotation it is not clear whether Heron only knew these three principles or whether he was rather correcting the text of Euclid at his disposal by deleting principles that he considered to be of no use. Proclus, for his part, thought that $\mathrm{CN} 4$ and $\mathrm{CN} 5$ should be counted among the common notions; but, once again, we do not know whether he did this on philological or rather on mathematical and philosophical grounds. Since Proclus added that these axioms are needed in order to prove the Euclidean theorems, the latter option seems to be the more likely and it is not clear that Proclus had any textual reason to attribute them to Euclid. As a matter of fact, some demonstrations of the Elements in which these principles do not appear are reformulated by Proclus so as to include an explicit reference to them. ${ }^{29}$

The Arabic commentary on the Elements by al-Nayrīzī (tenth century) incorporates sections of a (now lost) commentary on the Elements by Simplicius, who had, in his turn, been able to rely on Heron's commentary. And here Simplicius plainly states that only the first three common notions are Euclid's, thereby also implying that Heron himself may have recognized no more than these three as authentic. ${ }^{30}$ Simplicius' testimony is especially important, since he claims to have had access to "more ancient manuscripts" of the Elements which only reported three common notions. We are thus informed of the existence of two textual traditions of the Elements: an older one, closer to Euclid's own times, reporting only three common notions, and a more recent one which also added CN4 and CN5.

In light of the extant evidence, I would advance the hypothesis that in Heron's times the Elements only contained three common notions. It is possible, however, that other principles were to be found in the commentaries and the literature on elementary mathematics already in Heron's times. Should this have been the case, Heron would have been defending the original text of the Elements by stating that further principles were not needed. I may add that we have no evidence that Heron was aware of either $\mathrm{CN} 4$ or $\mathrm{CN} 5$, which are nowhere mentioned in his geometrical works - even in cases that would seem naturally to call for their being mentioned. ${ }^{31}$

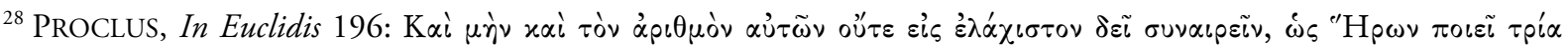

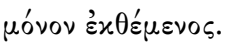

${ }^{29} @ 60$. The most outstanding case for CN4 is probably Elements I, 4, in which Euclid's alleged reference to this common notion is inferred by few words, whereas Proclus articulates at length its role in the demonstration (In Euclidis 240-41). As for CN5, Proclus offers an alternative demonstration of Elements I, 6 mentioning explicitly this principle (In Euclidis 257), adding that Euclid uses it in Elements I, 39 (In Euclidis 407), in Elements I, 40 (In Euclidis 411), and that it is required to prove the converse of Elements I, 41 (In Euclidis 414).

30 R.O. BeSTHORN, J.L. HeIBERG (eds.), Codex Leidensis 399,1: Euclidis elementa ex interpretatione AlHadschdschadschii cum commentariis Al-Nairizii, Copenhagen, Gyldendel 1893-1932, vol. 1, pp. 28-29; and in English translation A. LO BELLO (ED.), The Commentary of Al-Nayrizi on Book I of Euclid's Elements of Geometry, Leiden, Brill 2003, p. 99.

${ }^{31}$ In particular, Heron's Metrica would have been a perfect place to employ both CN4 and CN5 for a theory of

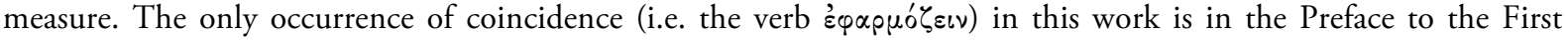
Book, in which Heron tersely says that right angles and segments are congruent to one another. In the case of segments, Heron does not even mention that they have to be equal and may have simply had in mind that they are homeomeric (cf. PROCLUS, In Euclidis 237-38, for a similar reference). Nowhere in the work is mention made of the principle stating that the whole is greater than the part (or even of the Euclidean expression regarding the lesser and the greater). For a recent edition of this work, see F. ACERBI, B. VitraC (eds.), Héron d'Alexandrie. Metrica, Pisa, Serra 2014. The same happens in Heron's Definitiones, where the notions of whole and parts are dealt with at length (Def. 120), without mentioning CN5. In the same passages (Def. 117), equality among figures is defined as two

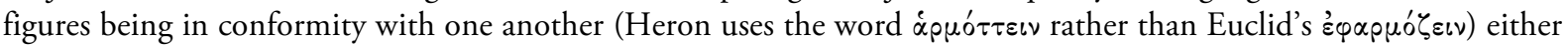
"according to the part" (i.e. if the parts of the figures are congruent one by one) or "according to the configuration"
} 
In particular, they do not appear in any of the surviving alternative or additional proofs provided by Heron in his commentary on the Elements. ${ }^{32}$

There is, however, a complication here. A single Arabic manuscript containing al-Nayrīzīs commentary features a marginal scholium about mathematical principles, reporting Heron's opinion on the latter. This scholium offers a peculiar fourfold division of principles based on epistemological considerations and states that, according to Heron, one of these four sorts of principles are the "common notions", examples of which are that two things equal to a third are equal to one another $(\mathrm{CN} 1)$, and that the whole is greater than the part (CN5). ${ }^{33}$

It is difficult to understand what to do with this single anonymous, isolated remark. We know that Heron's commentary on Euclid had been translated into Arabic, and therefore it is possible that the scribe (twelfth century) still had a manuscript of it when he copied al-Nayrīzīs text, and could, therefore, add such a marginal note. ${ }^{34}$ It may seem a bit odd that (according to Proclus) Heron only accepted three Euclidean common notions, thus rejecting CN5 from their list, while nonetheless, in discussing the epistemology of common notions, explicitly mentioning CN5 as one of them (as in the Arabic scholium). Of course, this constitutes no strong evidence against the reliability of the scholium. It might be that Heron did recognize $\mathrm{CN} 5$ as a common notion (an evident proposition, according to the epistemology of the scholium), because he found it either in the Elements or in some deuteronomic texts, but still thought that it was useless for the deductive structure of Euclidean geometry. There is also another possibility, however: namely, that even if the epistemological classification reported by the scholium is truly Heron's, the examples are not. This happened frequently in late antiquity. For instance Alexander, Themistius, Philoponus, and Simplicius all systematically exemplified the Aristotelian notion of a "common axiom" by mentioning $\mathrm{CN} 3$ and $\mathrm{CN} 1$ : the former is an actual quotation from Aristotle's works (where such an axiom does appear), but the latter (CN1) is never mentioned by Aristotle himself and is added by the commentators relying on the text of the Elements. Similarly, we may imagine that the Arabic scholiast provided himself with examples of Heron's common notions by mentioning $\mathrm{CN} 1$ and $\mathrm{CN} 5$, even though the latter was not referred to by Heron himself. This hypothesis may be reinforced by the fact that the list of common notions in al-Nayrīzìs commentary (as in many other manuscripts of the Elements) begins with $\mathrm{CN} 1$ and ends with CN5 (after mentioning many other axioms both authentic and spurious). The scholiast might, then, simply have wanted to refer to the list of principles involved by mentioning the first and the last items of it. The scholium is, therefore, no compelling evidence that CN5 had already been added to the text of the Elements in the times of Heron.

In conclusion: with the exception of Heron's reference in the Arabic scholium, CN4 and $\mathrm{CN} 5$ are never mentioned in any extant sources predating the fifth century $\mathrm{CE}$. While this cannot be considered a proof of inauthenticity, it seems to me to constitute a very strong clue that these common notions were later interpolations.

(i.e. if the figures are themselves congruent). I would guess that a clearer reference to $\mathrm{CN} 4$ would have been appropriate here, if Heron had known of it.

${ }^{32}$ Al-Nayriziz's commentary reports several of Heron's proofs. Nonetheless, none of the additional demonstrations mentioned in this commentary make use of CN5, and CN4 is only mentioned twice by Al-Nayrizizi (BESTHORN, HEIBERG, Codex Leidensis, vol. 1, pp. 80-81 and 112-13) in proofs that are explicitly not ascribed to Heron (and that Heiberg took for Arabic).

${ }^{33}$ BESTHORN, HeIBERG, Codex Leidensis, vol. 1, pp. 38-39.

${ }^{34}$ Gregg De Young has informed me that the hand in which this marginal scholium is written is the same hand as copied the whole text. Of course, it is possible that the scholium was already added in the source manuscript. 
We can make an educated guess concerning who interpolated them. We know that Theon of Alexandria (fourth century CE) made an "edition" ('x $\delta \mathrm{o} \sigma \iota s)$ of the text of the Elements, from which almost all surviving Greek manuscripts derive. Scholars largely disagree on the actual extent of Theon's interventions but, as far as I know, no one has suggested the possibility that these may have included the addition of CN4 and CN5 (or other axioms). The main reason for the neglect of this hypothesis lies in the famous Vatican manuscript of the Elements. Heiberg claimed, in fact, that this manuscript - which lists the nine common notions usually found in other Byzantine sources - displays a text predating Theon's edition. More recent studies, however, have proven that the Vatican manuscript results from a contamination of a nonTheonine version of the Elements with Theonine manuscripts. This being the case, it can be easily explained why the scribe might have included Theon's principles in the manuscript for the sake of completeness. ${ }^{35}$

The timeline of the sources dovetails nicely with this hypothesis. Indeed, not a single one of the sources prior to Theon quotes $\mathrm{CN} 4$ or $\mathrm{CN} 5$, whereas virtually all the sources after Theon's edition (Proclus, Simplicius, Philoponus) do quote them. This also applies to the Latin tradition: ps.-Censorinus and Capella, who lived before Theon, only knew the first three common notions; Boethius, who lived after Theon, also mentions CN4 (and possibly knew others). ${ }^{36}$

We may envisage, of course, a more complicated process of textual modification than the punctual intervention of an editor. We may easily imagine, for example, that several different versions of Euclid's Elements were circulating in antiquity, and that for a long time the text remained plastic and changeable. We have no reason to suppose, however, that a great number of systems of common notions had been devised before late antiquity. The main sources at our disposal, Proclus and Simplicius, seem to be aware of two different traditions of the Elements, with two different lists of common notions: an older tradition with few principles, and a more modern one with quite a few more. The wide dissemination of Theon's version of the Elements, testified to by all the Greek manuscript that have come down to us, is a good hint that Proclus and Simplicius may have been acquainted with this edition as well as with "more ancient" manuscripts predating Theon's intervention (Proclus was born around the same period in which Theon died; Simplicius a century and a half later). It is also true, however, that neither Proclus nor Simplicius explicitly mention Theon. It is possible that further historical accidents concerning the Byzantine transmission of the text have surreptitiously amplified the role of Theon's edition in modern studies on Euclid. It is also possible, then, that Theon's edition was one among several late editions of the Elements, and that the interpolation of the principles is rather due to some other editor or scribe. ${ }^{37}$ Should we want to adopt a more skeptical attitude on the issue, it still seems likely that the interpolation of common notions CN4 and CN5 happened, if not in Theon's work, at least in some other edition dating from the third or fourth century CE.

\footnotetext{
${ }^{35}$ Important studies on the Vatican manuscripts are those by W.R. KNORR, The Wrong Text of Euclid: On Heiberg's Text and its Alternatives, "Centaurus", 36 (1996), pp. 208- 276; and S. RommeVAuX, A. DJeBBAR, B. VitraC, Remarques sur l'Histoire du Texte des Éléments d'Euclide, "Archive for History of Exact Sciences", 55 (2001), pp. 221 295.

${ }^{36}$ Capella was actually a contemporary of Theon. Clearly, however, he did not rely on recent or updated bibliography in mathematics but rather on derivative texts of (more ancient) editions of the Elements. Given the fragmentary character of Boethius' text, I do not think that anything can be inferred from the fact that it does not refer to $\mathrm{CN} 5$.

${ }^{37}$ It is possible, for instance, that the transition from papyrus to parchment (which may have occurred in the thirdfourth century) could have given rise to new editions of the text of the Elements and modifications thereof.
} 


\section{\$3. Euclid's Theory of Equivalence}

Let us now turn to investigating the meaning and the role of common notions in Euclid's Elements. I will suggest that the first three common notions were first conceived in order to construct a geometrical theory of equivalence. Their occurrences and function within the deductive structure of the Elements seem, indeed, clearly to point in this direction. In fact, however, this theory of equivalence does not make use of CN4 and CN5 and, understandably, the meaning of these common notions has been the subject of much debate among interpreters. I eventually conclude that a uniform reading of the five common notions as axioms of a theory of equivalence is a viable option, but that it is nonetheless unlikely that the CN4 and CN5 were originally formulated by Euclid.

It is well known that Euclid had no conception of area or volume in the modern sense and made no use of numbers in order to express the measure of things. Rather, in order to "measure" figures, Euclid transformed a figure into another figure equivalent to it (i.e., in modern terms, with the same area or volume) having a standard shape-generally a parallelogram or a square. More often, Euclid constructed a rectangle equivalent to a given rectilinear figure and having a given base: the original figure was then said to have been "applied" to the given base, and therefore to have been measured in this way. The technique just described is called the "application of areas" and may be looked upon as a fragment of a more general theory of equivalence, or theory of content. A theory of content is distinguished from a theory of measure insofar as the latter employs a real-valued function to express the measure of a figure, whereas the former simply compares figures with one another in terms of the lesser, the equal and the greater. Theories of content have been studied and axiomatized in modern times and Hilbert famously offered the foundations for one of them in his Grundlagen der Geometrie from 1899. Hilbert's axiomatization, like many others, is largely inspired by Euclid's five common notions. ${ }^{38}$

Euclid's theory of equivalence is expounded at several points in the Elements and may derive from different sources. The most important section in this regard is the cluster of theorems making up Elements I, 35-45 and achieving the construction of a parallelogram equivalent to any given polygonal figure. It is very likely that this battery of propositions formed a single, cohesive essay that was possibly composed by Eudoxus and that Euclid included in the Elements as the culmination of Book I. ${ }^{39}$ A further collection of theorems on the same topic is constituted by the

\footnotetext{
${ }^{38}$ D. HilberT, Grundlagen der Geometrie, Leipzig, Teubner $1968\left(1899^{1}\right)$. See also U. AMALDI, Sulla teoria della equivalenza, in F. Enriques (ed.), Questioni riguardanti le matematiche elementari, Bologna, Zanichelli $1912\left(1900^{1}\right)$, vol. 1, pp. 145-198, which gives a modern reading of the role of Euclid's five common notions in the theory of equivalence. A more recent formalization of the same theory, which is more faithful to Euclid's Elements, is to be found in K. Robering, 'The Whole is Greater than the Part.' Mereology in Euclid's Elements, "Logic and Logical Philosophy", 25 (2016), pp. 371-409. It should be noticed that Greek mathematicians freely employed the word $\mu \varepsilon \tau \rho \varepsilon i \nu$, to measure, to designate what we call today a theory of content. According to this usage, a figure measures ( $\mu \varepsilon \tau \rho \varepsilon i \nu)$ another figure by being taken as a unit of measure of the latter. I have stuck to the modern terminology to avoid possible misunderstandings.

${ }^{39}$ A convincing argument for taking Elements I, 45 as the culmination of Book I of the Elements is given by Mueller, Philosophy of Mathematics and Deductive Structure, pp. 16-27. The deductive structure of Book I, in fact, seems to point to the proof of Elements I, 45, and Euclid may have arranged the previous propositions in order to prove this momentous result. In this respect, the following propositions of Elements I, 46-48, which together form
} 
fourteen theorems of Book II, ending with a proposition showing how to construct a square equivalent to a given parallelogram and thus, coupled with Elements I, 35-45, making it possible to square any rectilinear figure. Some theorems of Book II are further reformulated in Book VI (see especially Elements VI, 1, and 25, 28, 29), where the consideration of similar figures allows for important generalizations.

The foundations of the whole theory are to be found in the Eudoxian essay in Book I. The theorems expounded here seem to have been relatively new in Euclid's day and the results of Book II and VI appear to predate Eudoxus' foundational essay. Still earlier versions of an elementary theory of equivalence may have been based on a simpler cut-and-paste procedure, traces of which we still find in Plato, Aristotle and other ancient authors. This procedure allowed the cutting of a figure into triangles and the further rearrangement of these latter into another, equivalent figure. This older technique may be called a theory of the equidecomposability of figures. ${ }^{40}$

Eudoxus' more refined technique complemented equidecomposability with a parallel notion of equiampliability, according to which two figures are equal if it is possible to add to them equal figures and obtain equal figures. Eudoxus' refinement here is substantial: from a foundational point of view, equiampliability is distinctly stronger than equidecomposability, unless one also accepts the (so-called) Axiom of Archimedes. Eudoxus could not have been aware of the latter fact, which is quite hard to prove, but it is remarkable that he clearly saw the foundational advantages of availing himself of equiampliability in key theorems such as Elements I, 37 and Elements I, $44 .^{41}$ The elegant theory of equivalence of Elements I, 35-45 follows out of this idea. In it, Euclid (or Eudoxus) teaches how to construct a parallelogram equal to a given triangle and how to decompose all rectilinear figures into triangles and transform these, one by one, into adjacent parallelograms with the same angle and height. Following this procedure, Euclid is able to construct a bigger parallelogram made of several segments, each equal to one triangular part of the original figure. As a result, Euclid succeeds in transforming the original figure into an equivalent parallelogram (say, a rectangle of unitary height) and thus in "measuring" it. In this connection, the word "parallelogram", or better "parallelogrammic region" ( $\pi \alpha \rho \alpha \lambda \lambda \eta \lambda$ ó $_{\text {r }} \alpha \mu \mu \mathrm{o \nu}$ $\chi \omega^{\prime}$ prov), is used by Euclid in order to express the content of a rectilinear figure. This more abstract

\footnotetext{
Pythagoras' Theorem, should not be regarded as the final aim of Book I (as it was commonly stated), but rather as an appendix of sorts. The Eudoxian paternity of the theory expounded in Elements I, 35-45 has been advanced by E. NEUENSCHWANDER, Beiträge zur Frühgeschichte der griechischen Geometrie I, "Archive for History of Exact Sciences", 11 (1973), pp. 127-133.

${ }^{40}$ In the Timaeus, 53c, Plato exploits the fact that any surface may be decomposed into triangles in order to suggest that composition and decomposition of figures into triangles may explain the elemental changes. Aristotle further insisted that every figure may be decomposed into triangles in De an. B 3, 414b20-32. The above mentioned NEUENSCHWANDER, Beiträge I, provides some arguments claiming that the decomposition of a figure into triangles is of Pythagorean origin. Book II of the Elements was possibly elaborated by Theodorus, from earlier Pythagorean sources, in the generation before Eudoxus: see W. KNORR, The Evolution of the Euclidean Elements, Dordrecht, Reidel 1975, pp. 193-203. Decomposing and recomposing equivalent figures in order to compare them is a widelyused practice with immediate practical uses and even recreational ones-the most outstanding example in Greek antiquity possibly being the game of Stomachion, discussed by Archimedes.

${ }^{41}$ See HILBERT, Grundlagen der Geometrie, chap. 4, $\$ 19$, pp. 72-73. Books V and XII of the Elements, heavily relying on the Axiom of Archimedes (and explicitly so), are also attributed to Eudoxus. Cf. also a reference to such a principle in ARIST. Phys. $\Theta 10,266 \mathrm{~b} 2-4$.
} 
"parallelogrammic region" is the closest Greek equivalent to the modern idea of a class of equivalence of equal figures. ${ }^{42}$

It should be noted, however, that the theory of equivalence expounded in the whole of the Elements is stronger than this one through equiampliability. In Book V, indeed, Euclid (or Eudoxus, who may have conceived this theory as well) extends the considerations on content through a theory of proportions. More importantly, in Book XII he makes use also of the socalled method of exhaustion in order to compare the content of curvilinear figures that cannot be decomposed into congruent triangles. In the stereometric books, the theory of equiampliability cannot be applied as such to solid figures and different techniques are worked out. ${ }^{43}$ Needless to say, such practices acquired even more relevance in post-Euclidean advanced theory of content, such as in Archimedes' quadrature of the parabola or in his construction of a triangle equivalent to a circle. In short, ancient mathematics knew non-elementary techniques for ascertaining equivalence and therefore the Greek notion of "equality" cannot be reduced to equiampliability.

If we take Elements I, 35-45 as a foundational essay on the elementary theory of equivalence, we may surmise that it was axiomatized by Eudoxus himself. We have already seen, in fact, that we have independent evidence (namely, the testimony of Aristotle) for attributing the common notions to Eudoxus, or at least to some mathematicians among his contemporaries. It is immediately clear, on the other hand, that $\mathrm{CN} 1-\mathrm{CN} 3$ easily represent the most obvious principles for grounding a theory of equidecomposability and equiampliability of figures. By these common notions, the geometer is allowed precisely to decompose (subtracting equals from equals) and reconstruct (adding equals to equals) figures that are equal (i.e. equivalent in content) to one another. It is difficult even to imagine a more appropriate use of these common notions than such a theory, and I may conjecture that they were originally conceived in precisely this geometrical setting and later generalized to numbers and magnitudes in general. We have remarked already, indeed, that the use of $\mathrm{CN} 1-\mathrm{CN} 3$ in the arithmetical books of the Elements is minimal, and even their presence in Book V (the Eudoxian book on the theory of proportions) is not very apparent. On the contrary, the proofs of Elements I, 35-45 are based on some sixteen different uses of CN1-CN3; the proofs of the fourteen propositions of Book II are based on some thirty different uses of them; and all of CN1-CN3 are also employed in Elements VI, 28 and 29.44

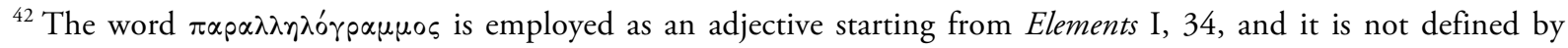
Euclid, who rather gives definitions of the actual figures (rectangle, square, and others) that are "parallelogrammic". In the Data, Euclid applies the expression "given in magnitude" to plane areas only in the case of circles and "parallelogrammic regions", thus showing that every polygonal figure, thanks to Elements I, 35-45, is subsumed under the latter label. In this respect, a parallelogrammic region is not much a figure, but rather a more abstract representation of content. The older Book II dealt only with shaped rectangles and squares, and this practice seems to be reflected in a passage in ARISTOT. De an. B 2, 413a16-17 (also only mentioning rectangles and squares). We

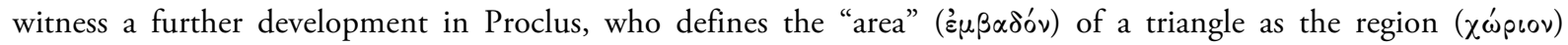
comprehended by the sides of the triangle, and "equal" triangles having equal $\varepsilon^{\prime} \mu \beta \alpha \delta \dot{\alpha}$ (In Euclidis 236). The term ¿̇ $\mu \beta \alpha \delta \delta^{\prime} v$ appears in Heron's Metrica, but is never to be found in Euclid or Hellenistic mathematics.

${ }^{43}$ For the failure of a theory of equiampliability for polyhedra (already suspected by Gauss), see the foundational discussion in HILBERT, Grundlagen der Geometrie, chap. 4, $\$ 21$, pp. 81-82, grounded on the important paper by M. DEHN, Über der Rauminhalt, "Mathematische Annalen", 55 (1902), pp. 465-78.

${ }^{44} \mathrm{Cf}$. the tables in VITRAC, Les Eléments, vol. 1, pp. 514-15, and vol. 2, p. 557. A close number is to be found also in the reconstruction by E. NEUENSCHWANDER, Die ersten vier Bücher der Elemente Euklids: Untersuchungen über den mathematischen Aufbau, die Zitierweise und die Entstehungsgeschichte, "Archive for History of Exact Sciences", 9 (1973), pp. 325-380. I may remark that the older theory of the application of areas expounded in Book II makes use almost exclusively of $\mathrm{CN} 2$, as do the theorems on equidecomposability of Book I, that may have predated those on
} 
None of these propositions could ever be proven without assuming these axioms. It seems therefore a reasonable guess that, if $\mathrm{CN} 1-\mathrm{CN} 3$ were first devised in Athens at the times of Eudoxus, and the theory of equivalence was first logically established in these same years, the three common notions were in fact originally conceived merely for use within the scope of this theory and later generalized.

A deeper and more difficult question concerns the role played by CN4 and CN5 in the theory of equivalence. Euclid's theory of equiampliability does not make any explicit use of these notions, and - as we have seen - they are never mentioned either in Elements I, 35-45, or in Book II, or in the generalization of the latter in Book VI.

From a purely mathematical point of view, one might conceive of $\mathrm{CN} 4$ as a kind of substitute for modern axioms of congruence. According to this interpretation, CN4 would be needed to ground the basic results regarding the congruence of triangles, which are proven through superposition and are a prerequisite for the theory of equiampliability. This does not seem, however, to have been the Greek understanding of the deductive flow. Foundational results regarding the congruence of triangles do play a role in the key proof of Elements I, 34, which is the starting point for the deductive machinery of the "essay" composed by Elements I, 35-45. This proposition only employs, however, the Angle-Side-Angle congruence theorem for triangles (Elements I, 26), which is the only congruence theorem for triangles that is not proven by Euclid through superposition. This oddity has been several times remarked upon by historians: two criteria of congruence out of three are proven by superposition (Elements I, 4 and 8) but Elements I, 26 is not. This can probably be explained by imagining a different pre-Euclidean source for the latter theorem (possibly proven in conjunction with Elements I, 34, and Elements I, 35-45). It is true that the demonstration of Elements I, 26 does in turn require Elements I, 4 (and is therefore based, in the last analysis, on superposition) but it is not obvious that the author of the essay on the theory of equiampliability, making use of Elements I, 26, realized, or believed, that equiampliability was based on superposition. ${ }^{45}$

A further argument to this effect is that the theory expounded in Elements I, 35-45 could have been simplified if its author had consented to straightforwardly employing superposition in the proofs of these eleven theorems. The most basic examples are given by Elements I, 36 and Elements I, 38, which would become redundant (with reference to Elements I, 35 and 37, respectively) if superposition were allowed. It seems clear that Eudoxus was working here outside of that tradition of Greek mathematical practices which employed superposition.

A similar case may be made for CN5. In modern axiomatizations of elementary theories of equivalence, CN5 is often reformulated as the so-called De Zolt's Postulate, stating that, if a polygon is dissected into polygons, the disjoint union of all these polygons except one is not equivalent to the initial polygon. It may be shown that De Zolt's Postulate is needed in the proof of Elements I, 39, stating that equal triangles with equal bases have the same height. Hilbert took this theorem to express that polygons are not all equivalent to one another, and regarded De

equiampliability requiring $\mathrm{CN} 3$. It may be conjectured, then, that $\mathrm{CN} 2$ had been devised earlier than $\mathrm{CN} 3$, and that the latter was first conceived with the introduction of equiampliability during the era of Aristotle (who explicitly mentions CN3 as a newly-discovered principle). Should this be the case, and referring further to note @64, one may suppose that the historical order of introduction of the common notions was $\mathrm{CN} 2$, then $\mathrm{CN} 3$, then CN1.

${ }^{45}$ Elements I, 4 is absolutely necessary for establishing a theory of content, and Hilbert proved in fact that a "nonPythagorean" geometry may be built by assuming a weaker form of this theorem (i.e. Hilbert's Axiom III 5). In such a geometry, CN4, CN5 and Elements I, 39 fail, and there are figures in part-whole relation having equal content. Cf. HilberT, Grundlagen der Geometrie, appendix 2, pp. 152-53. 
Zolt's Postulate to be the key assumption in this connection. ${ }^{46}$ The reading of CN5 as a formulation of De Zolt's Postulate is, however, clearly quite implausible from a historical point of view. There is no indication whatsoever that Euclid or any other ancient mathematician ever entertained the idea that one would need a theorem (Elements I, 39) or an axiom (CN5) in order to deny that all figures are equal to one another. ${ }^{47}$

To sum up, then, we have no evidence that any Greek mathematician regarded CN4 and $\mathrm{CN} 5$ as principles grounding the theory of the equiampliability of polygons.

\section{\$4. An Extended Axiomatics for Diagrammatic Inferences}

Sources leave us at a loss concerning the role of CN4 and CN5 in the foundations of ancient mathematics. They do not appear and indeed are not required (as far as Greek demonstrative practices are concerned) in any theorem of the Elements.

Even in the case - a case for which I have argued - where CN4 and CN5 prove not to be Euclid's, the problem remains of understanding why these common notions should have been added to Euclid's text in late antiquity. The few modern interpreters who deny the authenticity of CN4 and CN5 generally think that these common notions were added to the text in order to

\footnotetext{
${ }^{46}$ For CN5, see HilberT, Grundlagen der Geometrie, chap. 4, $\$ 19$, p. 74. De Zolt's Postulate was first introduced in A. DE ZOLT, Principii della egualianza di poligoni preceduti da alcuni cenni critici sulla teoria della equivalenza geometrica, Milano, Briola 1881. Later on, the postulate became a theorem, insofar as it was proven by Schur from other assumptions, including the Axiom of Archimedes. Hilbert gave a complete proof of it independent of this latter axiom. See R. Hartshorne, Geometry. Euclid and Beyond, New York, Springer 2000, p. 210, stating that a proof of it without passing through a notion of measure has not yet been found. For modern treatments of De Zolt's Postulate in relation to CN5, see the more historical VOLKERT, Le tout est-il toujours plus grand que la partie?, and the more mathematical E.N. Giovannini, E.H. HäUsler, A. Lassalle-Casanave, P.A.S. Veloso, De Zolt's Postulate: An Abstract Approach, "The Review of Symbolic Logic", published online. I may remark that from a modern, set-theoretical point of view, there are useful reformulations of the part-whole principle (CN5), as well as of the two "Aristotelian Principles" (CN2 and CN3). Their deductive relationships are quite complicated, and on some hypotheses it is possible to prove (modern versions of) CN2 and CN3 from (a modern version of) CN5. For some investigations in this direction, see P. MANCOSU. B. SISKIND, Neologicist Foundations: Inconsistent Abstraction Principles and Part-Whole, in G.M. Mras, P. Weingartner, B. Ritter (eds.), Philosophy of Logic and Mathematics: Proceedings of the $41^{\text {st }}$ International Ludwig Wittgenstein Symposium, pp. 215-248, Berlin, De Gruyter 2019.

${ }^{47}$ Elements I, 39 is never used again in the theory of equivalence, nor anywhere else in the Elements, and no special foundational value seems to be attached to it; for the role of Elements I, 39 in the demonstration of the other theorems of the Elements, see HARTSHORnE, Geometry. Euclid and Beyond, p. 203. I have mentioned above (see note @60) that Proclus recognized the foundational role of CN5 in Elements I, 39. He surely did not interpret this proposition, however, as one stating the impossibility that all figures are equivalent to one another. In the Eudoxian essay on equiampliability, the formula "the less would be equal to the greater", which is taken by some interpreters to signal an application of CN5, is also used in Elements I, 40. The latter proposition is, however, surely spurious: it was added for symmetry with Elements I, 39, and it is not contained in an old papyrus fragment. See J.L. HEIBERG, Paralipomena zu Euklid, "Hermes. Zeitschrift für classische Philologie", 38 (1903), pp. 46-74, 161-201, 321-356 (p. 50). Note that also in this Fayyum papyrus (probably second-third century CE) the demonstration of Elements I, 39 makes use of the usual expression "the greater to the less" (as do all the Greek manuscripts that we possess), and that there is no mention of the whole and the part.
} 
fill some deductive gaps in the proofs. ${ }^{48}$ This seems to be the case, indeed, with several other interpolated (and surely spurious) common notions. ${ }^{49} \mathrm{I}$ would, however, resist such a proposal. We have already seen that Elements I, 4, for instance, is based on at least three different assumptions regarding equality and congruence, all of them equally evident to the reader: congruent figures are equal, equal segments are congruent, equal angles are congruent. Just as it is implausible that Euclid might have spelled out CN4 and neglected the other two, I would say that any editor of the Elements willing to fill the deductive gaps of this proposition would have added at least three axioms. As a matter of fact, this did occur in many early modern editions of the Elements. ${ }^{50}$ A similar case may be made for $\mathrm{CN} 5$, which does not appear to have been devised in order to justify the occurrences of the expression "the less would be equal to the greater" in reductio proofs. The latter statement immediately points to an obvious contradiction in terminis and does not seem to require any axiomatic foundation-surely not one referring to the whole and the part. I would, therefore, reject the hypothesis of an interpolation of CN4 and CN5 as two independent "fixes" of local textual issues.

In view of the complete silence on this question of all the sources at our disposal we have to try a different approach in order to figure out the motives for the addition of CN4 and CN5. We do, indeed, know a great deal about Greek mathematical practices and ancient axiomatics in general. In light of what we know about these, one may indeed venture a speculation as to why someone after Euclid might have felt the need to complement the latter's three common notions with more axioms. We may be guided here by some important hints. The two axioms CN4 and CN5 are always mentioned together by our sources, and therefore seem to require a unitary explanation. Moreover, we have seen that CN1-CN3 were probably originally devised in order to ground a theory of equivalence, and they may have been regarded as axioms of such a theory for many centuries after Euclid. It is therefore likely that $\mathrm{CN} 4$ and $\mathrm{CN} 5$, added to these principles, were themselves conceived with a view to grounding a theory of content. This suggestion is in agreement with the modern mathematical understanding of these principles, even if the details

\footnotetext{
${ }^{48}$ See, for instance, HeAth, The Elements, vol. 1, p. 248. MuEller, Philosophy of Mathematics and Deductive Structure, p. 35, denies that CN4 was interpolated from Elements I, 4, but does not offer any further reason for its addition.

${ }^{49}$ For example, that "the doubles of the same thing are equal" is an assumption used in the proof of Elements I, 47; that "the halves of the same thing are equal" is used in Elements I, 37 and 38; that "if equals are added to unequal things, the wholes are unequal" is used in Elements I, 19 and 21; that "two straight lines do not encompass a space" is used in Elements I, 4 and then in Elements XI, 3 and 7. Some of these principles may have been added to the main text of the Elements and to the list of common notions at the same time. If Euclid had already included the statement about "halves of the same thing" in the proofs of Elements I, 37 and 38, expressed twice with the same words, it seems that he would also have included it as a common notion from the very beginning. It is more likely that Euclid simply made an inference without mentioning the halves and a later editor (or two different editors) added a piece of text pointing to the need for assuming the principle on halves in these propositions and a corresponding common notion at the beginning of the treatise. This, at least, was the opinion of Heiberg; for a contrary opinion, see Mueller, Philosophy of Mathematics and Deductive Structure, pp. 34-35. Should this be true in general, it is possible that no common notions were added to the Elements in antiquity by extracting them from Euclid's text.

${ }^{50}$ We find already in Proclus' commentary (In Euclidis 184 and 240-41) the observation that in Elements I, 4 Euclid is employing the converse of $\mathrm{CN} 4$, an axiom which is false in general but true if restricted just to straight segments and rectilinear angles. The same is repeated in Campanus' edition (mid-thirteenth century), and the principle was later to be stated as an axiom in the Euclidean editions by Claude Richard (1645), Andreas Tacquet (1654), Isaac Barrow (1655), Gilles-François de Gottignies (1669), Milliet Dechales (1672), Mercator (1678), Abraham Kästner (1758), and others. Clavius (1574) prefers to conclude the proof of Elements I, 4 through the axiom that two straight lines cannot have a common segment, also derived from Proclus (In Euclidis 214).
} 
may need to be further refined (as is the case with CN5 and De Zolt's Postulate). I will, therefore, explore this hypothesis and offer an interpretation of CN4 and CN5 that may explain their significance as principles of Greek mathematics.

As I see it, CN4 and CN5 do indeed contribute to the axiomatization of a theory of equivalence and complement Euclid's common notions of equiampliability. The role played by $\mathrm{CN} 4$ and $\mathrm{CN} 5$ in this theory is, however, different from that of CN1-CN3. These additional axioms are used to compare to one another the squares (or parallelogrammic regions) that have been obtained through the process of equiampliability. This comparison is, in a sense, the goal of the theory of equivalence itself and in this respect $\mathrm{CN} 4$ and $\mathrm{CN} 5$ may be regarded as the crowning of the axiomatic system for such a theory. In another sense, however, CN4 and CN5 are external to the theory itself. They do not need to be embedded into a deductive chain of propositions (such as Elements I, 35-45); rather, they are directly employed in order to compare figures: there is nothing to prove by them. This may explain why Euclid's original theory made no use or mention of these axioms and at the same time why they may have been perceived as a necessary addition to Euclid's axiomatics in a different intellectual context. The latter conclusion may be strengthened by looking at the epistemology underlying these common notions. The comparison of figures through CN4 and CN5 occurs by means of diagrammatic inferences, whereas $\mathrm{CN} 1-\mathrm{CN} 3$ are purely propositional principles. It is perfectly reasonable, then, that Euclid may have only allowed propositional axioms in the foundations of mathematics and regarded diagrammatic inferences as non-axiomatic. Later ancient mathematicians, however, endorsing different epistemological views, may have felt the need of adding axioms for governing diagrammatic reasoning. It may be suggested, therefore, that, looked at from a certain epistemological perspective, CN1-CN3 do together form a sufficient set of axioms for the theory of equivalence (Euclid's own system); while, looked at from a different epistemological perspective, they need to be supplemented by CN4 and CN5.

I will now substantiate this interpretation.

Common notions CN4 and CN5 may be read as principles of a theory of content. Accordingly, CN4 would state that superposed figures are equal in content and $\mathrm{CN} 5$ that the whole is greater in content than the part. After the transformation of any polygonal figure into an equivalent square (thanks to equidecomposability and equiampliability techniques), the resulting squares may be compared with one another by superposing them. ${ }^{51}$ Through superposition, we may order the figures in terms of content, by saying that a figure is greater in content than another if it contains the other. In order to make such a comparison, we need CN4 to say that the smaller figure, which is superposed to a part of the larger figure, is equal in content to such a part. We then need $\mathrm{CN} 5$ to conclude that the larger figure is greater in content than its part and therefore greater than the other figure. In this respect, the procedure of decomposition and squaring allowed by $\mathrm{CN} 1-\mathrm{CN} 3$ is complemented by a further process resulting in the comparison of figures, this being based on CN4 and CN5. The five common notions together thus allow the comparison of any two polygonal figures and the establishing of whether the first is greater, equal or less in content than the second. The words "equal" and "greater" have, therefore, a uniform

\footnotetext{
${ }^{51}$ It is immaterial, for my interpretation, whether Euclidean superposition is interpreted as an actual displacement of figures or rather (as suggested by Zeuthen and others) as a re-construction of a given figure in another position. Note that thanks to the results of Elements II we may also just compare the sides of the squares (i.e. segments), again by means of $\mathrm{CN} 4$ and $\mathrm{CN} 5$.
} 
meaning in all five common notions, evoking as they do the theory of content of geometrical figures. ${ }^{52}$

According to this interpretation, $\mathrm{CN} 4$ may be read as complementing $\mathrm{CN} 5$ insofar as the former axiomatizes a condition for the equality of the content of figures and the latter axiomatizes a condition for their ordering.

Indeed, we may go further than this and say that the two common notions are strictly linked together inasmuch as they both refer to the technique of superposition, which is the proper ground of the ancient comparison of figures. The possibility of superposition is not itself axiomatized in Greek geometry, but it is rather grounded on intuition and diagrammatic inferences. ${ }^{53}$ This is especially relevant in assessing the significance of CN4 and CN5 and a unitary interpretation of these principles may in fact be based on actual ancient mathematical practices.

Greek geometry did not in general allow the drawing of conclusions about measure (and therefore about equality and inequality) on the basis just of inspection of a diagram. It is not, for example, allowed in ancient geometry to infer that the exterior angle of a triangle is greater than the opposite internal angles just by looking at a diagram. In order to arrive at such conclusions Greek geometers were of the view that propositional arguments and principles were needed. Nevertheless, in some cases Euclid did feel authorized to say that something is greater than something else just by looking at the diagram: namely, in all cases in which the lesser is a part of the greater. Thus, for instance, Euclid constructs a certain angle and then draws a further line from the same point, which happens to fall inside the angle. By inspecting the diagram he concludes that the first angle is greater than the second, since the latter is a part of the former. Similarly, if a triangle is contained within a square, the square will be greater than the triangle. In fact, in these cases Euclid never provides any argument whatsoever. This sort of evident conclusion is, in fact, not peculiar to Euclid but is a standard procedure found in all geometrical texts of antiquity. ${ }^{54}$

In short, in Greek mathematics the mereological relation of parthood is always diagrammatically inferred. The notion of "greater than", on the contrary, requires a propositional articulation and proof. I would claim that $\mathrm{CN} 5$ should be interpreted as a principle axiomatizing this widespread ancient practice. It has the form of an inference connecting, on the one hand, a mereological relation read off from a diagram (this figure contains that figure) with, on the other hand, a propositional statement on content and measure (this figure is greater in content than

\footnotetext{
${ }^{52}$ This notwithstanding, I do not think we should accept the highly anachronistic interpretation of CN1-CN5 as giving an implicit definition of the relation of "being equal/greater in content". In fact, we have no hint of any ancient discussion in epistemology (such as Aristotle's) suggesting that a system of axioms could ever work as a definition. For this anachronistic interpretation, see HEATH, The Elements, vol. 1, p. 325; and K. VON FRITZ, Die APXAI in der griechischen Mathematik, "Archiv für Begrifsgeschichte", 1 (1955), pp. 13-103.

${ }_{53}$ This first happened in modern-age editions of Euclid; Claude Richard's Elements, for example, have a postulate stating that any two figures may be displaced and superposed at will. Cf. C. RICHARD, Euclidis elementorum geometricorum libros tredecim, Antwerp, Verdus 1645, p. 10.

${ }_{54}^{4}$ The distinction between diagrammatic and "exact" properties was introduced into scholarly debate by a paper by Kenneth Manders. Manders did not deal with the ancient theory of measure, nor did he mention CN5, but he already recognized parthood as a relation individuated by the diagram. See K. MANDERS, The Euclidean Diagram, in The Philosophy of Mathematical Practice, ed. P. Mancosu, Oxford, OUP 2008, pp. 80-133 (especially pp. 91 and 112). Several formal treatments of these ideas has been offered in the literature. See for instance the important J. Avigad, E. Dean, J. Mumma, A Formal System for Euclid's Elements, "The Review of Symbolic Logic", 2 (2009), pp. 700-768, which has a discussion on diagrams and common notions in p. 741.
} 
that figure). As such, $\mathrm{CN} 5$ expresses an aspect of the interplay between diagrammatic and propositional reasoning in Greek geometry. It plays, therefore, a significant epistemic role in ancient mathematics and its explicit formulation (whenever it first appeared in antiquity) must be regarded as a historical landmark in the development of the epistemology of geometry. Ancient commentators seem to have realized this fact and indeed they call upon CN5 in the proofs of Euclid in which he had drawn a conclusion on measure starting from a diagrammatic inference. ${ }^{55}$

I may remark that this interpretation establishes, indeed, a certain actual connection between CN5 and the standard Euclidean formula "the less would be equal to the greater" that many interpreters would like to see either as an enthymematic formulation of CN5 (if they take this principle to be authentic), or as the main textual reason for this latter's later interpolation (if they take this principle to be spurious). The conclusion regarding the less and the greater is entirely propositional but Euclid usually ascertains it by looking at the diagram and then inferring a statement about the respective size of two figures. In this sense, many of Euclid's conclusions to the effect that "the less would be equal to the greater" are in fact based on implicit applications of CN5 (see for instance Elements I, 6). This is, however, not always the case. There are also many proofs in which Euclid concludes from a part-whole relation seen in the diagram to a propositional statement about size, which are not proofs by reductio and do not mention the formula on the greater and the less (e.g. Elements I, 7 or Elements I, 20). And there are proofs in which the reductio argument is applied after its having been propositionally proven (i.e. proven without any diagrammatic inference or use of $\mathrm{CN} 5$ ) that a certain figure would be greater, or less, than another figure (e.g. Elements III, 13). Therefore, if we accept that CN5 was devised with a view to grounding a theory of equivalence, we cannot connect it in a standard way to the more generic Euclidean formula "the less would be equal to the greater". As a matter of fact, the formula is employed by Euclid in countless propositions that have nothing to do with the theory of content (e.g. in Elements III, 1, which teaches how to find the center of a given circle). In this respect, even though there is a connection between the formula and $\mathrm{CN} 5$, their meaning and aims may have been widely different.

This reading of $\mathrm{CN} 5$, moreover, is at odds with a more logical reading of it as a sort of definition or tautological statement. According to the logical interpretation, the words "is greater than" in the formulation of CN5 would simply mean "contains" and would express a mereological rather than a content-theoretical statement. As a consequence, the common notion would state that the part is contained in the whole, or perhaps that a part is indeed a proper part of the whole (i.e. is not identical with it). A similar interpretation was already advanced by Ibn alHaytham in the Middle Ages and was further exploited by Leibniz in the seventeenth century, and later adopted by a few modern interpreters. ${ }^{56}$ I cannot find any evidence, however, that such

\footnotetext{
${ }^{55}$ See the occurrences of CN5 in Proclus' commentary, always referring to part-whole relations read off from the diagrams: In Euclidis 257, 264, 296, 407, 408, 414.

${ }^{56}$ Ibn al-Haytham's interpretation and syllogistic proof of CN5 can be found in his famous Optics (II, III, $\$ 32$ ) and in his second commentary on Euclid (On the Resolution of Doubts in Euclid's Elements). For an English translation of the Optics, see A.I. SABRA (ed.), The Optics of Ibn Al-Haytham, London, Warburg Institute 1989, vol. 1, p. 133. The commentary on Euclid has not been translated into English but the relevant discussion may be found in IGHBARIAH, WAGNER, Ibn al-Haytham's Revision. Leibniz proved CN5 several times in his writings. The first instance may have been in the Demonstratio propositionum primarum from 1671-1672 (A VI, 2, n. 57, pp. 482-83; cf. also A II, 1 , n. 109, p. 355). On Leibniz's proof see M. FICHANT, Leibniz et l'exigence de démonstration des axiomes: 'La partie est plus petite que le Tout', in M. Fichant, Science et métaphysique dans Descartes et Leibniz, Paris, PUF 1998, pp. 329-73. A similar stance on the analyticity of CN5 was taken in 1866 by Jean-Marie-Constant Duhamel, who is regarded as
} 
an interpretation was ever held in antiquity and all ancient commentators on CN5 seem to regard this latter as a substantial (i.e. non-trivial) principle about content. In conclusion, CN5 should not be interpreted in modern terms as a definition or an analytical statement about mereology but rather as a "synthetic" axiom putting into relation with one another the mereological structure and the content-theoretical structure of geometrical figures (i.e. their "measure"). These two different domains, which were of course not thematized as structures in pre-modern geometry, were still regarded as separate in Greek mathematics insofar as they were governed by different deductive practices: diagrammatic and propositional. ${ }^{57}$

I would interpret CN4 in terms similar to those in which I have interpreted CN5. This common notion, stating that congruent figures are equal, is used to move from superposition to equality of content: superposition is intuitively given, equality must be propositionally established. In this sense, CN4 plays the same epistemic role as CN5 inasmuch as it makes it possible to move from a visual, non-propositional procedure (superposition and coincidence) to a propositional statement about exact properties (equality).

The diagrammatic nature of $\mathrm{CN} 4$ is revealed especially clearly by the fact that Greek mathematics possessed no proper concept of congruence as a relation between figures. The

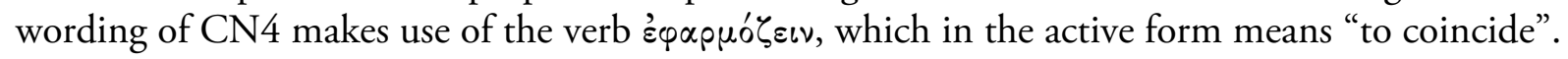

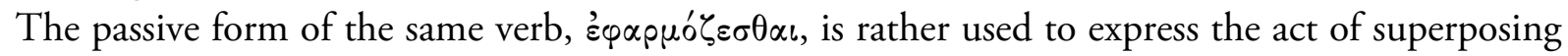
two figures (be they coincident or not). In Euclid's Elements, however, there is no occurrence of the active form which is not preceded by the passive one. In short, "coinciding" or "being

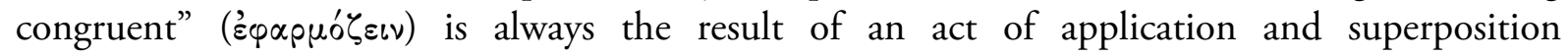
$\left(\dot{\varepsilon} \varphi \alpha \rho \mu^{\prime} \zeta \varepsilon \sigma \theta \alpha \iota\right)$ and two figures cannot, here, be said to be congruent in any case where they are not actually applied to one another. Euclid sometimes employs the expression " $\sigma \alpha$ $\alpha \alpha i$ ó $\mu \circ \tilde{\alpha} \alpha$ ("equal and similar" figures) to convey the idea that two figures that are not actually superposed are nonetheless "congruent" in our sense. ${ }^{58}$ The "' $\sigma \alpha$ xai ó $\mu$ oi $\alpha$ expression, however, is never

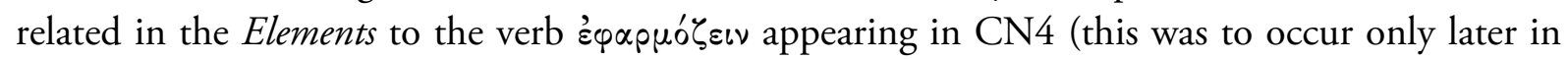
the history of Greek mathematics). More often, Euclid simply calls "equal” non-superposed

one of the first mathematicians interested in grounding an axiomatic theory of equivalence in elementary geometry. See J.-M.-C. Duhamel, Des méthodes dans les sciences de raisonnement, Paris, Gauthiers-Villars 1865-1873, vol. 2, p. 7; and the historical remarks in K. VOLKERT, Le tout est-il toujours plus grand que la partie?, "Revue d'histoire des mathématiques", 16 (2010), pp. 287-306.

${ }^{57}$ I would formally express the meaning of $\mathrm{CN} 5$ as an axiom on the monotonicity of content: $A \sqsubset B \rightarrow A \preccurlyeq B$. It may be compared to the modern axiom of the monotonicity of measure, which is generally stated in the form $A \subset B \rightarrow$ $m(A) \leq m(B)$, where the order-relation of set inclusion entails a similar order of the measure of sets. The latter formula should be adjusted in several respects to fit with the Greek theory of content. First of all, the set-theoretical inclusion (c) should be transformed into the relation of parthood in a mereological framework (ᄃ), since CN5 is formulated in mereological terms. Second, the ordering between real numbers as outputs of the measure function $(<)$ must be transformed into an ordering relation $(\prec)$ between geometrical figures. The latter ordering relates to the content of a figure, and may be applied, of course, also to figures that are not in a part-whole relation but are equiampliable to such figures. The formula is, however, not even restricted to polygonal figures (as, for instance, De Zolt's Postulate), insofar as the Greek theory of equivalence had a broader scope than an elementary theory of equiampliability and admitted advanced techniques such as exhaustion. In Euclid's proofs, CN4 would apply, for instance, to circular arcs in Elements III, 24, and CN5 would apply to circles and squares in Elements XII, 2.

${ }^{58}$ The expression appears in Elements XI, def. 10 to define what we would call congruent polyhedra. Already in Book VI, however, Euclid had inferred that two polygons having equal area and being similar to one another must have equal sides (cf. Elements VI, 22). 
figures that are actually congruent with one another. ${ }^{59}$ Moreover, no theorem of the Elements (or

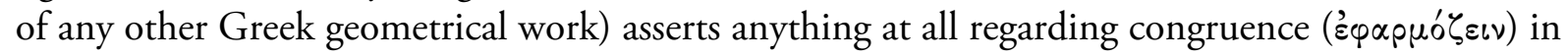
its statement; the verb is only used in the course of the demonstrations and it signals a technique rather than a relation between figures. ${ }^{60} \mathrm{In}$ conclusion, $\mathrm{CN} 4$ cannot be read as a purely

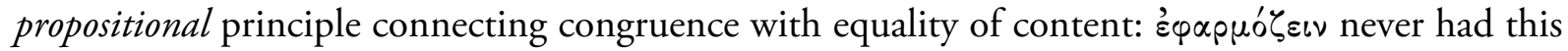
abstract meaning but rather only the operational and diagrammatic significance of establishing equality of content through actual superposition.

The whole Greek theory of measure in geometry is, therefore, grounded on the intuitive basis of comparing figures through superposition and it comes as no surprise that so many epistemologies of mathematics developed in antiquity stressed the role of sensible or imaginative knowledge in the foundations of this science. I will not belabor the point here any further, but it seems clear that CN4 and CN5 are the core principles axiomatizing this interplay between intuition and rational discourse.

\section{\$5. Conclusions}

We may sum up the above investigations by saying that the most straightforward interpretation of the meaning of the five common notions $\mathrm{CN} 1-\mathrm{CN} 5$ is that they served to ground a theory of equivalence in geometry. This set of principles may fall short of being a flawless system according to modern standards; but it surely represents a remarkable landmark in studies on the foundations of the theory of measure, providing as it does an axiomatic foundation for a theory making it possible to move from the notion of "figure" as a shaped magnitude to the more abstract notion of "content" ${ }^{61}$

We have also seen, however, that this system of principles naturally divides up into two very different subsets.

Common notions CN1-CN3 together provide a neat axiomatization of equality and additivity. While they may have first been conceived in geometry, they are easily and flawlessly generalized to numbers and magnitudes in general, thus fitting in with the Aristotelian remarks

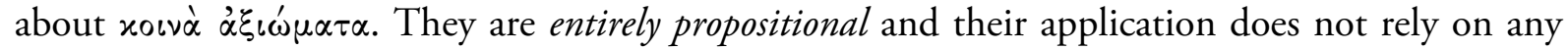
diagrammatic inference. Taken together, they are used by Euclid and his predecessors to ground a

\footnotetext{
${ }^{59}$ It is well known that Euclid employs the expression '̈ $\sigma \circ \varsigma$ in the first thirty-four propositions of Book I (i.e. before the essay of Elements I, 35-45) to refer to congruent figures. I do not think that this expression should be read as enthymematic for "congruent and therefore equal in content". On the contrary, equal triangles are here (e.g. Elements, I, 16, 33, 34) simply congruent triangles, and Euclid's proofs would generally not work if these triangles were equal in measure but not also equal in shape. This is a general phenomenon. Equal angles are in fact congruent angles (as it was noted already in antiquity: cf. Proclus, In Euclidis 189-90, and my own discussion in Euclid's Fourth Postulate, forthcoming). In Book III, equal circles are obviously congruent circles rather than circles equal in measure (even if the two classes have the same extension), and in Elements III, 23-24 Euclid calls "equal circular arcs" figures that must be congruent in order for the demonstration to succeed (cf. HEATH, Euclid. The Elements, vol. 2, p. 53). The examples might be further multiplied. On Euclid's "flou" terminology of equality and congruence, see also VITRAC, Les Éléments, vol. 1, pp. 502-12.

${ }^{60}$ A general discussion of Euclid's notions of equality and "congruence" may be found in K. vON FrITZ, Gleichheit, Kongruenz und Ähnlichkeit in der antiken Mathematik bis auf Euklid, "Archiv für Begriffsgeschichte", 4 (1959), pp. 7 81.

${ }^{61}$ For a modern axiomatic treatment of the subject, complementing Euclid's common notions with further principles, see MUELlER, Philosophy of Mathematics and Deductive Structure, pp. 36-37.
} 
theory of equivalence based on equiampliability. They are in fact systematically exploited in the crucial sections of Euclid's treatise concerning the elementary theory of content: Elements I, 3545, Elements II, 1-14, and Elements VI, 28-29.

Common notions CN4 and CN5 likewise form, taken together, a highly cohesive pair. Despite their different formulations, their meaning and use appear to be closely related to one another and designed to provide a comparison of the content of figures by superposition. They are more clearly geometrical than are $\mathrm{CN} 1-\mathrm{CN} 3$ and probably cannot be applied to numbers and general magnitudes, thus failing to qualify as common axioms in the Aristotelian sense. Moreover, they are both diagrammatical and used to bridge the gap between intuitive evidence and propositional content. Being geometrical and diagrammatical, they seem, therefore, to reflect a different epistemology than that reflected in the other three common notions. Their tasks as regards the theory of content are also different. They are never quoted or referred to in the Euclidean essays on the equivalence of figures and they play no role in establishing the equidecomposability and equiampliability techniques. Their function in the theory of content, by contrast, is a crucial one, yet nevertheless somehow external to the main mathematical results: $\mathrm{CN} 1-\mathrm{CN} 3$ are used to square polygonal magnitudes through a variety of different theorems and results, whereas $\mathrm{CN} 4$ and $\mathrm{CN} 5$ are only applied at the end of this procedure to compare squares with one another. No theorem, problem or other proposition is used or needed in order to achieve this end and it is not surprising that the Elements do not contain any explicit reference to this last step in the determination of content. In a sense, the squaring of polygons through equiampliability is all that is looked for in mathematics and the further comparison of squares falls outside the scope of demonstration.

The interpretation of common notions as two blocks of principles conforms with the conclusions of our textual analysis, showing that the evidence for the authenticity of CN1-CN3 is quite strong, whereas $\mathrm{CN} 4$ and $\mathrm{CN} 5$ only appear much later, in the indirect sources, and are always paired together.

The most natural conclusion to be drawn from these considerations is that a first group of common notions concerning equality - namely CN1-CN3 - was conceived already in the times of Eudoxus and Aristotle while a second group of common notions concerning superposition and comparison of figures - namely CN4-CN5 - was later added to the previous three in order to have a complete axiomatization of the elementary theory of content. We have seen that a likely date for this addition to the Elements is the fourth century CE, but it is also possible that CN4 and $\mathrm{CN} 5$ had originally been devised some time before they found their way into the text of Euclid. The sources at our disposal do not allow us to make any conclusive statement to this effect.

We may imagine that CN4 and CN5 were conceived (for example) by Hellenistic mathematicians in order to ground a theory of equivalence for curvilinear figures (quadrature of the circle, the parabola, etc.), for which equiampliability and CN1-CN3 would have proven insufficient just in themselves. It is also possible that Archimedes' and Apollonius' more careful distinctions between equality and congruence may have given rise to a general reflection on the principles grounding the theory of equivalence, which then resulted in the formulation of new axioms. It is even possible that someone like Theon simply added such common notions for explanatory or didactic purposes: even though they are not employed in the theory of content of the Elements, they nonetheless play a foundational role in comparing figures once they have been squared with the tools of Book I and II. 
In the absence of any textual evidence to this effect, I will not advance further conjectures regarding the specific circumstances of an interpolation. I may, however, remark that the general idea of spelling out principles able to bridge the gap between diagrammatic inferences and propositional content seems to be a recurrent feature of later reflections on the Elements. Whereas Euclid proceeded sometimes in a purely diagrammatic way, ancient commentators added these bridge-principles, possibly in order to comply with new epistemological ideas about the role of imagination in mathematics. ${ }^{62}$

This reconstruction of the possible motives for the interpolation of CN4 and CN5 remains conjectural. It has been proposed in order to reconcile what seems the obvious mathematical meaning of these principles with the textual evidence at our disposal and mostly relies on a certain global understanding of the development of Greek mathematics. The conjecture complements some more robust (even if negative) evidence that CN4 and CN5 were indeed interpolated into the Elements in the era of Theon and represents an attempt to put together the many scanty pieces of evidence on the early history of Euclidean axiomatics.

\footnotetext{
${ }^{62}$ I have claimed that Euclid's definition of a point as the boundary of a line was interpreted (possibly already by Euclid, but possibly by Pappus) as a principle complementing a diagrammatic inference with a propositional statement, in order to ground a theory of intersections. I have also advanced the conjecture that the fourth postulate of the Elements, stating that all right angles are equal, was interpolated in the age of Apollonius in order to provide another similar principle bridging the gap between diagrams and propositions. See V. DE RISI, Gapless Lines and Gapless Proofs. Intersections and Continuity in Euclid's Elements, "Apeiron", 2019; V. DE RISI, Euclid's Fourth Postulate, forthcoming.
} 